\title{
On the Prediction of Ground-Reflected Solar Radiation and its Relevance in the Context of Building Performance Simulation (BPS)
}

\author{
Luminita Dumitrascu $^{1}$, Ian Beausoleil-Morrison ${ }^{1}$ \\ ${ }^{1}$ Carleton University, Ottawa, Canada
}

\begin{abstract}
Establishing accurate ground reflectivity values is critical for the reliable prediction of ground-reflected solar radiation. It is common for building performance simulation users to employ the default values of ground reflectivity ( 0.2 for most simulation tools) which can lead to significant inaccuracies, especially for periods during which the ground is covered by snow.

The paper provides an overview of existing models for predicting ground reflectivity, and then presents a new model suitable for implementation into BPS tools. Simulation results predicted with the new model are further compared with measurements.

To quantify the influence of the new model, two sets of simulations were run with ESP-r to predict the solar irradiance incident on a south oriented façade and on a south oriented $60^{\circ}$-sloped surface. Comparing the predictions with measured data, it was noticed that the influence of the new model on predicted solar irradiance is higher for the vertical surface.
\end{abstract}

\section{Introduction}

The accurate prediction of solar radiation incident upon building surfaces and solar collectors is imperative for accurate thermal simulations. The solar radiation incident on a surface is commonly calculated as the sum of three components: direct beam, sky diffuse, and ground reflected (Duffie \& Beckman, 2013). Depending on the nature of the surface or season, the ground-reflected component can represent a substantial fraction of the total solar radiation incident on a specific surface, and hence its accurate prediction is critical.

The presence of snow can increase the reflectivity of the ground from about 20\% to more than $80 \%$ (Nkendirim, 1972), which substantially increases the solar radiation incident on building surfaces, particularly vertical surfaces such as windows and facades. Therefore, the accurate prediction of ground reflectivity, especially considering the impact of accumulating and melting snow, is critical in cold climates (Hunt \& Calafell, 1977).

Direct surface measurements of ground reflectivity are rarely available in the weather files commonly employed in building and solar system simulation tools. Furthermore, such data might contain large errors if the instrumentation is not properly monitored and maintained (Gardner \& Sharp, 2010). Consequently, a pragmatic way forward is the development of models that can predict ground reflectivity based upon commonly measured environmental parameters.

Starting in early 1960 s, ground reflectivity models were developed under a wide range of snow and atmospheric conditions. Depending on their application (earth's heat balance, climatological models, urban heat island effect, performance of solar collector, building energy simulation) these models required inputs such as solar zenith angle, snow depth, snow age/rate of decay, concentration of light-absorbing particles, cloud cover index, and ambient temperature (Gardner \& Sharp, 2010). However, models predicting the ground/snow reflectivity have not been greatly investigated in the context of BPS. Currently, there are only two models predicting the reflectivity of snow-covered ground, both developed by Thevenard and Haddad in 2006. Their "simple" model predicts the reflectivity based on the user-input number of days of snow cover per month, while the "advanced" model forms an energy balance on the ground surface to determine when snow is melting and adjusts the userinput reflectivity for fresh snow based upon the predicted melting time. The "advanced" model requires hourly or daily snow depth data, a parameter not available in most commonly employed weather files.

The Thevenard and Haddad models have been implemented in ESP-r but are not available in other simulation tools such as EnergyPlus and TRNSYS. Moreover, they are rarely used due to a lack of the required snow depth data in commonly used weather files. Consequently, most BPS and solar simulation tool users rely on tool default methods and values.

This paper presents some of the factors influencing the solar reflection by the ground and some models previously developed for predicting ground reflectivity. A new model that considers the effects of accumulating and melting snow is also described. The new model is cast in a form that is suitable for inclusion in BPS and solar simulation tools and operates on data that are available within commonly used weather files. To quantify the influence of the new model, two sets of simulations were run with ESP-r to predict the solar irradiance incident on a south oriented façade and on a south oriented $60^{\circ}$-sloped surface. The predictions were compared with measured data and the results of this comparison are presented further. A short description of other potential applications of the model is following. Finally, some concluding thoughts are presented at the end of the paper. 


\section{Factors influencing solar reflection by the ground and previous models}

\section{Factors affecting ground/snow reflectivity}

According to the literature (Nkendirim, 1972), (Arnfield, 1975), the nature of the surface considered, the solar elevation/zenith angle and the cloud cover are among the factors with significant influence on reflectivity.

Investigating the relationship between reflectivity and solar zenith angle for various surfaces, Nkendirim (1972) observed a strong exponential relationship with the solar zenith angle. The dependence of reflectivity on solar zenith angle was noticed to be more significant in days with clear sky, and almost insignificant on overcast days. A field study was conducted at Urbandale Centre for Home Energy Research (CHEeR), Carleton University, Ottawa, for a fifteen-month period (December 2016-April 2018). Point measurements of global horizontal and reflected solar radiation were taken with the purpose of deriving a model for predicting snow/ground reflectivity. Figure 1 illustrates the daily variation of reflectivity with the solar zenith angle for three representative types of cloud cover: clear sky, mixed sky or intermittent cloudiness, and overcast sky.
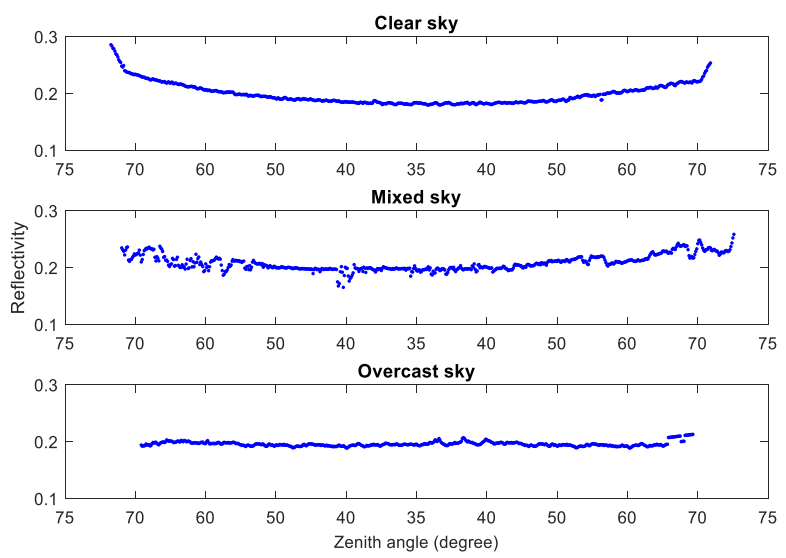

Figure 1: Daily variation of reflectivity with solar zenith angle and cloud cover.

Ground reflectivity increases from about $20 \%$ to more than $80 \%$ in the presence of snow (Nkendirim, 1972). The characteristic values of fresh snow reflectivity reported in literature are between 0.75 (Muneer, 1997) and 0.95 (Backer, Ruschy, \& Wall, 1990). In time, due to metamorphic processes, snow reflectivity decreases to values between 0.7 and 0.5 or less (Backer, Ruschy, \& Wall, 1990).

Data collected during the study conducted at Carleton University, as well as radiation and meteorological measurements from SURFRAD (Surface Radiation Budget Network) operated by NOAA (National Oceanic and Atmospheric Administration) were used to analyze the seasonal variation of reflectivity for various types of surfaces. Currently there are seven SURFRAD stations operating in climatologically diverse regions across the United States (National Oceanic and Atmospheric Administration, 2017). The SURFRAD datasets measurements include 1-min averaged values of various metrics used for energy balance applications in solar engineering. Daily averages of reflectivity were calculated for the year 2017 for all SURFRAD data sets, as well as for Ottawa, Canada. Figure 2 presents the variation of daily average reflectivity with the season, for Ottawa and some of the SURFRAD stations.

As Figure 2 illustrates, the results are consistent with the previous findings (Nkendirim, 1972), (Backer, Ruschy, \& Wall, 1990). Depending on climate, during the winter season, ground reflectivity increases significantly (average reflectivity 0.8 ) due to the presence of snow. It was noticed that reflectivity of snow surface can experience a high day to day variability, especially towards the end of the winter, when the snow melting season starts. By contrast, a naturally vegetated surface or bare ground registers a small daily variation, most of the time around the average value of 0.2 (Desert Rock, NV).

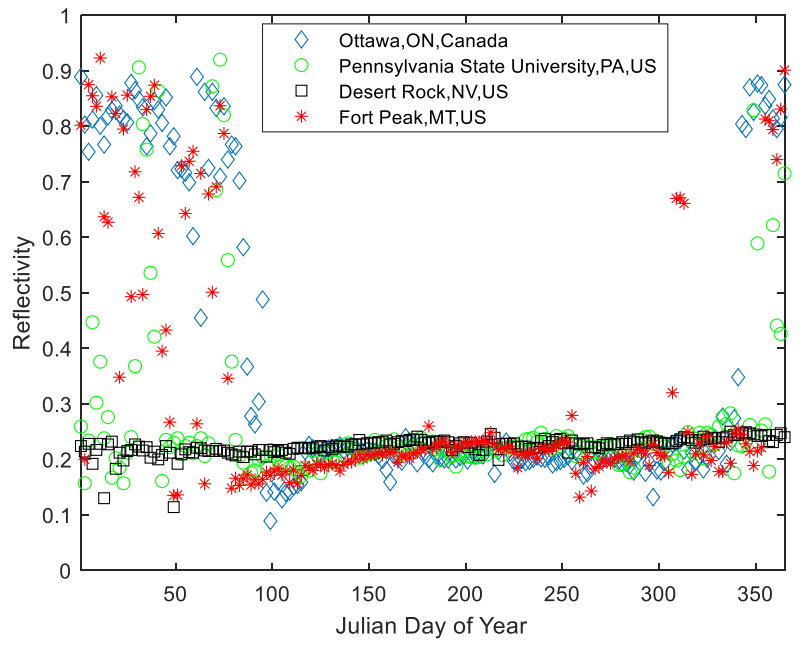

Figure 2: Seasonal variation of average daily reflectivity.

Several studies (Muneer, 1997), (Chen, Li, Li, \& Liu, 2014) and (Winther, 1993) show that the main factors influencing snow reflectivity are the following: snow age; snow grain size (melting leads to snow grains coalescence, decreasing the surface reflectivity); snow wetness (reflectivity decreases while the water content increases); accumulated depth; deposition of light absorbing particles as dust and soot; spectral composition and direction of the radiation; ambient temperature/solar radiation.

Another factor influencing snow reflectivity is the specular reflection. According to Duffie and Beckman (2013), for most ordinary surfaces, such as bare soil and vegetated ground, reflectivity is almost entirely diffuse. Dirmhirn and Eaton (1975) found that the reflectivity of fresh fallen snow is almost isotropic, while the specular component increases with the age of snow, and with the number of melting and refreezing processes towards the end of the cold season. They also observed that specularity can increase the reflected radiation either forward or backward. The forward scattering is strongly increasing with decreasing solar incidence angle, while the back scattering is very small, with no significant variation. A model accounting for specularity was 
developed by Gueymard (1987). Nevertheless, the ground reflected radiation calculated with his model was very close to the value provided by the isotropic case. Specularity can be treated in a more complex way but Thevenard and Haddad (2006) consider that the additional computational expense does not seem justified in the case of BPS.

\section{Some of the previous models predicting ground/snow reflectivity}

Starting in early 1960s, ground/snow reflectivity models were developed under a wide range of snow and atmospheric conditions, for various purposes. Depending on their application (earth's heat balance, climatological models, urban heat island effect, performance of solar collectors, building energy simulation) the models require input parameters such as: solar zenith angle, snow depth, snow age/rate of decay, concentration of light-absorbing particles, cloud cover index and temperature (Gardner \& Sharp, 2010). Table 1, presented at the end of the paper, summarises the functional form and the inputs required by some of the relevant models found in literature.

\section{A new model for predicting reflectivity}

\section{Data collection}

As was previously mentioned, a field study was conducted at Urbandale Centre for Home Energy Research (CHEeR) at Carleton University. CHEeR is located in a semi-open environment, characteristic of many suburban or rural developments, with the surrounding ground covered with short grass. Point measurements of global horizontal and reflected solar radiation were taken for a period of fifteen months (December 2016-April 2018).

The sensor used was a Kipp and Zonen CMA6 albedometer, which is sensitive to wavelengths of about 0.3 to $3.0 \mu \mathrm{m}$ (Kip and Zonen, 2013). The estimated instrument calibration uncertainty provided by the manufacturer was $\pm 2.57 \%$. From December 2016 to July 2017, the global horizontal and reflected solar radiation were sampled at one second frequency and averaged at five seconds time-interval using a National Instruments cFP 2220 data logger. The total bias error of the system albedometer-data logger associated with reflectivity calculation was found to be $\pm 8.4 \%$. For the period August 2017 - April 2018, the global horizontal and reflected solar radiation were sampled at ten seconds frequency, using a National Instruments PXIe 1078 data logger. This time, the total bias error associated with the reflectivity calculation was $\pm 5.7 \%$ due to this device's higher voltage resolution compared with the cFP 2220.

\section{Functional form}

After verifying the monitored data for consistency, and for detecting and removing the gross or "egregious" errors, an exploratory data analysis was performed. According to this, three periods were associated with major changes in values of reflectivity: ground free of snow; snow accumulation or non-melting; and snow melting.
Multiple linear regressions were performed to determine the coefficients for each period of interest.

\section{Ground free of snow period}

For Ottawa this season can be defined generally as the period starting in the second half of April, until the first half of November, when the ground is completely free of snow. Based on the observations made during the data exploratory analysis, the predictors for this period were found to be the zenith angle and sky transmissivity. Sky transmissivity $(\boldsymbol{S T})$, defined as the ratio between the global radiation incident on a horizontal surface and the extra-terrestrial radiation incident on a horizontal plane (Carroll, 1985), was used as an indicative of cloudiness.

The following functional form was established for this period:

$\rho=a+b \cdot\left[1-\cos \left(\theta_{z}\right)\right]+c \cdot S T-d \cdot\left(50-\theta_{z}\right)$

where $\boldsymbol{\rho}$ is reflectivity, $\boldsymbol{\theta}_{\boldsymbol{z}}$ is solar zenith angle [deg] and $\boldsymbol{S T}$ is sky transmissivity. The coefficients of the model ( $\boldsymbol{a}$, $\boldsymbol{b}, \boldsymbol{c}$, and $\boldsymbol{d}$ ) were determined for three types of cloud cover: overcast sky $(\boldsymbol{S T}<0.3)$, intermittent cloudiness or mixed sky $(0.3 \leq \boldsymbol{S T} \leq 0.6)$, and clear sky $(\boldsymbol{S T}>0.6)$. Table 2 presents the numerical values of the coefficients.

Table 2: Ground free of snow period, numerical values of the coefficients.

\begin{tabular}{|c|c|c|c|}
\hline Coefficient & $\begin{array}{c}\text { Overcast } \\
\text { sky }\end{array}$ & $\begin{array}{c}\text { Mixed } \\
\text { sky }\end{array}$ & $\begin{array}{c}\text { Clear } \\
\text { sky }\end{array}$ \\
\hline $\mathbf{a}$ & 0.140 & 0.160 & 0.170 \\
\hline $\mathbf{b}$ & 0.040 & 0.060 & 0.080 \\
\hline $\mathbf{c}$ & 0.040 & 0.040 & 0.040 \\
\hline $\mathbf{d}$ & 0.000 & 0.000 & 0.001 \\
\hline
\end{tabular}

Snow accumulation or non-melting period

Typically, this period starts at the end of November or beginning of December in Ottawa. During this period, there are frequent snow-falls and the decrease of reflectivity between two consecutive snow-fall events is relatively small.

A variable named snow age $(\boldsymbol{S A})$ is used during this period. This is calculated based on the observations made during the data collection period and is equal to the number of hours that have elapsed since the last snowfall.

For this period, the derived functional form was noticed to provide good results for all types of cloud cover, and it has the following expression:

$$
\begin{gathered}
\rho=0.85-0.03 \cdot\left[1-\cos \left(\theta_{z}\right)\right]-0.10 \cdot S T \\
-0.022 \cdot(S A / 24)
\end{gathered}
$$

where $\boldsymbol{\rho}$ is reflectivity, $\boldsymbol{\theta}_{\mathbf{z}}$ is solar zenith angle [deg], $\boldsymbol{S T}$ is sky transmissivity and $\boldsymbol{S A}$ is snow age [hours].

\section{Snow melting period}

Snow melting represents the period when changes to the optical properties of the snow cover, the effect of solar radiation penetrating the ground surface, and the development of patchy snow cover accelerate the decrease of reflectivity. Generally, this period is shorter compared with the ground free of snow and snow accumulation period. For Ottawa this period starts 
generally at the beginning of March and ends approximately mid-April, when the ground is completely free of snow. It should be noticed though that the melting period is highly dependent on location and the specific weather conditions. Multiple criteria, such as snow cover melting, decreasing rate of reflectivity, and ambient temperature should be considered when deciding the beginning of snow melting.

For this period, snowfalls are less frequent and the decrease in reflectivity between two consecutive snowfall events is significant. Contrary to the accumulation season, when the daily variation of reflectivity was noticed to have small values, for the snow melting period, the daily variation was noticed to have a wide range, for some days from 0.85 to 0.35 .

According to the observations made during the data collection period, in the morning, when the ambient temperature has generally negative or close to $0^{\circ} \mathrm{C}$ values, reflectivity decreases at a lower rate, comparable with the snow accumulation season. However, once the ambient temperature is larger than a so called "threshold temperature", which was noticed to change with the day of the year, the reflectivity decreases at a significantly higher rate.

Based on the work of McKay (1964), who found a relationship between the daily mean temperature above $0^{\circ} \mathrm{C}$ required for snow melting and the day of the year, the calculation of the threshold temperature was performed using the following expression:

$$
T_{\text {threshold }}=-0.06 \cdot n+6.7
$$

where $\boldsymbol{T}_{\text {threshold }}$ is threshold temperature, the temperature when the snow melting rate is higher than the melting rate characteristic for the snow accumulation period $\left[{ }^{\circ} \mathrm{C}\right]$ and $\boldsymbol{n}$ is the Julian day of the year.

During this period, the influence of the zenith angle is no longer significant, and the effects of snow melting are dominant. The predictors of the model were found to be the sky transmissivity $(\boldsymbol{S} \boldsymbol{T})$, snow age $(\boldsymbol{S A})$ and the difference between the ambient temperature and the threshold temperature calculated according to Eq. (3), $\left(\boldsymbol{T}_{\boldsymbol{a}}-\boldsymbol{T}_{\text {threshold }}\right)$. The functional form describing the relationship between variables was found to be a piecewise function having the following expression:

For $\left(\boldsymbol{T}_{\boldsymbol{a}}-\boldsymbol{T}_{\text {threshold }}\right)<0$

$$
\begin{gathered}
\rho=0.75-0.085 \cdot S T+0.012 \cdot\left(T_{a}-T_{\text {threshold }}\right) \\
-0.022 \cdot S A / 24
\end{gathered}
$$

For $\left(\boldsymbol{T}_{\boldsymbol{a}}-\boldsymbol{T}_{\text {threshold }}\right)>0$

$$
\begin{gathered}
\rho=0.75-0.115 \cdot S T-0.018 \cdot\left(T_{a}-T_{\text {threshold }}\right) \\
-0.050 \cdot S A / 24
\end{gathered}
$$

where $\boldsymbol{\rho}$ is reflectivity, $\boldsymbol{S} \boldsymbol{T}$ is sky transmissivity, $\boldsymbol{T}_{\boldsymbol{a}}$ is ambient temperature $\left[{ }^{\circ} \mathrm{C}\right], \quad \boldsymbol{T}_{\text {threshold }}$ is threshold temperature [ ${ }^{\circ} \mathrm{C}$ ], and $\boldsymbol{S A}$ is snow age [hours].

\section{Model validation}

The data sample constructed for each period was divided in two sets of data; one set was used for deriving the functional form while the other one for validating the model.
The analysis of residuals (the difference between the predicted and observed values of reflectivity) was performed for both data sets: the data set used to derive the functional form and the data set used for validation. The accuracy of the parametric model was assessed based on the following statistical metrics: mean absolute error (MAE), relative mean absolute error (rMAE), root mean square error (RMSE) and relative root mean square error (rRMSE). The values of these metrics, for each period of interest, are presented in Table 3.

Table 3: Statistical metrics - model validation.

\begin{tabular}{|c|c|c|c|}
\hline Metric & $\begin{array}{c}\text { Ground free } \\
\text { of snow }\end{array}$ & $\begin{array}{c}\text { Snow } \\
\text { accumulation }\end{array}$ & $\begin{array}{c}\text { Snow } \\
\text { melting }\end{array}$ \\
\hline \multicolumn{4}{|c|}{ Data set used to derive the functional form } \\
\hline MAE & 0.011 & 0.031 & 0.057 \\
\hline rMAE & $5.14 \%$ & $4.00 \%$ & $9.22 \%$ \\
\hline RMSE & 0.015 & 0.041 & 0.041 \\
\hline rRMSE & $7.00 \%$ & $5.29 \%$ & $11.48 \%$ \\
\hline \multicolumn{5}{|c|}{ Data set used to validate the model } \\
\hline MAE & 0.015 & 0.036 & 0.061 \\
\hline rMAE & $7.00 \%$ & $4.64 \%$ & $9.87 \%$ \\
\hline RMSE & 0.018 & 0.045 & 0.072 \\
\hline rRMSE & $8.41 \%$ & $5.80 \%$ & $11.65 \%$ \\
\hline
\end{tabular}

It can be noticed that the rMAE has values lower than $10 \%$ for each period, indicating a good agreement between the predicted and observed values. The highest value was registered for the snow melting period, when higher differences between the predicted and observed values were noticed for some intervals. However, given the small number of days displaying this behaviour, the overall influence is not significant.

The model was implemented in the ESP-r source code and the predictions of reflectivity were also validated. The validation was performed for 2017 , using three data sets: one collected at CHEeR and the other two using the radiation and meteorological measurements from SURFRAD (Fort Peck station, Montana and Sioux Falls, South Dakota). The accuracy of the ESP-r predictions was assessed based on the statistical metrics previously presented. The values for Ottawa and Fort Peak are presented in Table 4.

Table 4: Statistical metrics-ESR-r predictions.

\begin{tabular}{|c|c|c|c|}
\hline Metric & $\begin{array}{c}\text { Ground free } \\
\text { of snow }\end{array}$ & $\begin{array}{c}\text { Snow } \\
\text { accumulation }\end{array}$ & $\begin{array}{c}\text { Snow } \\
\text { melting }\end{array}$ \\
\hline \multicolumn{4}{|c|}{ Data sample: CHEeR, Ottawa } \\
\hline MAE & 0.017 & 0.068 & 0.062 \\
\hline rMAE & $5.24 \%$ & $7.34 \%$ & $9.03 \%$ \\
\hline RMSE & 0.021 & 0.070 & 0.075 \\
\hline rRMSE & $8.72 \%$ & $9.45 \%$ & $10.13 \%$ \\
\hline Independent data: SURFRAD Fort Peak Station \\
\hline MAE & 0.011 & 0.084 & 0.061 \\
\hline rMAE & $5.77 \%$ & $9.30 \%$ & $9.83 \%$ \\
\hline RMSE & 0.013 & 0.103 & 0.118 \\
\hline rRMSE & $7.07 \%$ & $9.78 \%$ & $11.06 \%$ \\
\hline
\end{tabular}


The results of the validation showed a good agreement between the predicted and observed values for both Ottawa and Fort Peak. For the Sioux Falls, significant differences were noticed for the winter season. As such, it was concluded that further research is required to calibrate the model for regions with mild winters.

\section{Observations of new model}

According to Equations (1) and (2), reflectivity is positively correlated with the solar zenith angle and sky transmissivity, and as such, reflectivity will have the highest value shortly after sunrise and before sunset, when the solar zenith angle is close to 90 degrees, under clear sky conditions.

During the ground free of snow period, it was noticed that the properties of the vegetated surface change with the season. Therefore, the value of coefficient $\boldsymbol{a}$ varies throughout the year. It was noticed that $\boldsymbol{a}$ has smaller values at the beginning and the end of the season (around 0.145), while during the middle of the season (the summer period) the value is higher (around 0.180). To keep the functional form of the model as simple as possible while providing accurate predictions, the coefficient $\boldsymbol{a}$ was calculated as a weighted average based on the monthly values.

Comparing the observed values of reflectivity with the predicted ones for individual days, a good agreement was noticed for most days. A higher difference was noticed in the morning and towards the end of the day, when the solar zenith angle has values higher than $80^{\circ}$, especially for days with clear sky. Nevertheless, given the small magnitude of the solar irradiance at the beginning and the end of the day, it can be assumed that the overall influence is not significant.

As Equations (2), (4), and (5) show, reflectivity and snow age are negatively correlated, and as such, reflectivity decreases with the increasing snow age. The difference between the daily average reflectivity for a day with fresh snow and the daily average reflectivity for the day before the next new snowfall event was calculated during the snow accumulation period. The daily decreasing rate of reflectivity was calculated as the ratio between this difference and the number of days between the two snowfall events. For the snow accumulation period the daily decreasing rate was found to be in the range of $0.4 \%$ to $3.8 \%$, with an average of $2.2 \%$, while for the snow melting period between $0.9 \%$ and $47.1 \%$, with an average of $17.1 \%$. It can be noticed that for the melting season, the decreasing rate of reflectivity is significantly higher compared to the accumulation season.

For most days with mixed and overcast sky, the predicted values of the model follow the trend of observed data very closely. However, for some days with clear sky, there are noticeable differences between the trends of observed and predicted data for some days. The bias of the model can be explained partly by the small number of full sunny days during the data collection period.

For the snow melting period, observations made during the data collection led to the conclusion that the decrease in reflectivity of late-occurring snow is significantly higher compared with the accumulation period, resulting in high variability from one day to another. The highest decrease in reflectivity was noticed when patches of bare ground are visible through the snow cover, and the fraction of incoming solar radiation absorbed by the ground is increasing. However, this transition period was noticed to be relatively short, spanning only 1 or 2 days.

Analysing the daily scatter plots of observed and predicted reflectivity versus the zenith angle, it was noticed that the predicted values follow the trend of observed data for most days, and for all types of cloud cover. The difference between the observed and predicted values was more noticeable in the case of discontinuous snow cover. Nevertheless, as was previously said, the number of such days is very small compared with the total number of days, and as such, their overall influence is not significant.

\section{The impact of the new model on prediction of solar irradiance incident on building surfaces}

As was mentioned before, depending on the nature of the surface or season, the ground-reflected component can represent a substantial fraction of the total solar radiation incident on surfaces having unobstructed views of the ground, and hence its accurate prediction is critical for predicting the energy use of a building or the performance of solar thermal or photovoltaic collectors.

To quantify the influence of the new model, two sets of simulations were run with ESP-r to predict the solar irradiance incident on:

- the south façade of CHEeR;

- the solar thermal collectors mounted on the southfacing roof of $\mathrm{CHEeR}\left(60^{\circ}\right.$ sloped surface)

Simulations were conducted with a weather file composed with the meteorological measurements taken at the CHEeR site.

Two simulations were performed with 1-minute timesteps: one using the new ground-reflectivity model presented in the previous section; the other using ESP-s default reflectivity treatment (a constant value of 0.2 ). The hourly averaged values of predicted solar irradiance were compared with measured values recorded at CHEeR.

The difference between the predicted and measured values was calculated for each day and for each month. Relative daily and monthly values were calculated by dividing this difference to the measured value. The relative monthly difference was calculated for the period January-December 2017. A positive value of the relative monthly difference indicates an overprediction while a negative value an underprediction relative to the measured values. Table 5, presented on the next page, illustrates the magnitude of the relative monthly difference for a whole year. It can be noticed that the impact of ground reflectivity on the prediction of incident solar irradiance is more significant in the case of the vertical surface. The higher view factor to the ground of the vertical surface might partially account for this. 
Table 5: The relative monthly difference between the predicted and measured solar irradiance.

\begin{tabular}{|l|c|c|c|c|}
\hline \multirow{2}{*}{ Month } & \multicolumn{3}{|c|}{ Relative monthly difference [\%] } \\
\cline { 2 - 5 } & \multicolumn{2}{|c|}{ New model } & \multicolumn{2}{c|}{ Default reflectivity } \\
\hline & Vertical & $\mathbf{6 0}^{\circ}$ - tilt & Vertical & $\mathbf{6 0}^{\circ}$ - tilt \\
\hline Jan. & 4.1 & 2.9 & -14.1 & -7.4 \\
\hline Feb. & 1.7 & 1.9 & -11.5 & -5.4 \\
\hline Mar. & 1.5 & 0.8 & -6.7 & -3.1 \\
\hline Apr. & 5.4 & 3.8 & 8.1 & 1.4 \\
\hline May & 5.7 & 4.9 & 7.8 & 1.1 \\
\hline Jun. & -4.8 & -2.7 & -5.6 & -3.2 \\
\hline Jul. & -4.1 & -2.9 & -4.9 & -3.1 \\
\hline Aug. & 1.2 & 2.1 & 1.0 & 0.3 \\
\hline Sep. & 4.1 & -1.2 & 5.4 & -0.3 \\
\hline Oct. & 4.5 & 2.1 & 6.2 & 1.6 \\
\hline Nov. & 3.9 & 2.5 & -1.7 & -0.2 \\
\hline Dec. & 4.3 & 2.9 & -5.8 & -1.9 \\
\hline Accoly
\end{tabular}

According to Table 5, the default treatment of reflectivity significantly underpredicts the solar irradiance during the winter, while the new model is tending to overpredict it. The overprediction of the new model might be partially explained by the prediction of snow when freezing rain is present. It was noticed that freezing rain decreases the reflectivity from the average value of 0.8 to less than 0.7 for a few days, until a new snow-fall event occurs, while the new model is increasing actually the reflectivity from 0.8 to more than 0.85 , depending on the duration of the snow-fall event. For the ground free of snow season, both the new model and the default reflectivity alternate between over- and underprediction, with the new model slightly closer to the measured values. This is due most likely to the variation of the vegetated surface properties with the season. It was also noticed that the new model is predicting better the hourly values, especially for days with clear sky, when the variation of reflectivity with the zenith angle is more noticeable.

\section{Other relevant applications of the new model}

Photovoltaic (PV) systems inside the urban environment might represent a viable solution to mitigate the large electricity demand in cities. For vertical surfaces such as facades and windows, depending on the nature of the surface or season, the ground-reflected component can represent a substantial fraction of the total solar radiation incident on building surfaces. Hence, the yield of PV systems mounted on facades can be predicted more accurately using appropriate values of ground reflectivity. A study was conducted at the University of Natural Resources and Life Sciences (BOKU) in Vienna, during August 2016 (Revesza, Oswaldb, Trimmelb, Weihsb, \& Zaminia, 2018) to investigate the potential contribution of ground-reflected irradiance to the electricity production of PV facades in an urban canyon. The gain in PV power output for a vertical, south-facing PV panel was evaluated for "low ground-albedo" (asphalt with $\boldsymbol{\rho}=0.13$ ) and "high ground-albedo" (reflective concrete with $\rho=0.5$ ). The estimated values of the PV yield were compared with measured values.

It was noted that in the morning and in the afternoon, the deviation between measurement and estimation is relatively larger than around mid-day. According to the authors (Revesza, Oswaldb, Trimmelb, Weihsb, \& Zaminia, 2018), this might be due to the difficulty of accurately estimating the portion of ground that is shaded by the building in the morning and the afternoon. Nevertheless, further investigation can be conducted using the new model for predicting reflectivity, that takes into account the diurnal variation of reflectivity with the zenith angle (Figure 1).

Bifacial solar photovoltaics is a promising technology that increases the production of electricity per square meter of PV module using the light absorption from the ground reflected solar radiation. Cuevas et al. (Cuevas, Luque, Eguren, \& DelAlamo, 1982) showed that 50\% increase in electric power generation can be obtained by simultaneously collecting direct and reflected solar radiation from the rooftop and surroundings around the module. Consequently, the bifacial solar cells can increase the power density of PV modules compared to monofacial cells while reducing area-related costs for PV systems.

Sun et al. (Sun, Khana, Delineb, \& Alama, 2018) have developed a comprehensive opto-electrothermal framework to study and optimize bifacial solar modules in a global context. According to their results, for a low ground reflectivity of 0.25 , the bifacial gain of ground mounted bifacial modules is less than $10 \%$ worldwide. However, increasing the ground reflectivity to 0.5 and elevating the modules $1 \mathrm{~m}$ above the ground can boost the bifacial gain to $30 \%$. The analysis was performed using constant ground reflectivity throughout the day. Further research can be conducted to investigate the impact of the new model, that takes into account the variation of reflectivity with the zenith angle and cloud cover.

\section{Conclusions}

Accurate prediction of building energy use or solar system performance requires appropriate values of snow/ground reflectivity. Usually, the reflectivity of a vegetated surface/bare ground has no significant variation from one day to another. However, depending on the environment, in the case of ground covered with snow, the reflectivity increases significantly (from around $20 \%$ to more than $80 \%$ ), and it can register important daily and long-term variations. Many times, the energy use peaks also during the winter season, and by taking advantage of the increased fraction of solar irradiance while designing new buildings or retrofitting the existing ones, the energy use of the built environment can be reduced.

An algorithm for predicting the reflectivity for both ground free of snow and ground covered with snow was presented. The significant change in reflectivity was noticed to be associated with three periods:

- Ground free of snow - no significant variation from one day to another, and daily reflectivity has small variations around the average value of 0.2 .

- Non-melting or snow accumulation - no significant variation from one day to another due to frequent snow falls, and small variation around the average 
value of 0.8

- Snow melting - significant variation from one day to another due to positive ambient temperatures and isolated snowfalls events.

The model was implemented in ESP-r, a building simulation tool. The predictions of the new model were validated using a sub-set of the data sample, and two independent data sets from locations with cold and humid climate, Fort Peck (Montana - US) and Sioux Falls (South Dakota - US). The results of the validation showed that the model is suited for regions with cold and humid climate, like Ottawa, Canada. For regions with mild winters, similar with Sioux Falls, further research is required to calibrate the model for these specific conditions.

The main contributions of this work are: (1) The model can predict the reflectivity for both seasons ground free of snow and ground covered with snow. (2) The reflectivity can be predicted based on metrics existing in the weather file used to drive the simulation, without requiring additional information from an external file. (3) The model was implemented in the ESP-r and is available for implementation in other simulation tools.

\section{References}

Agami Reddy, T. (2011). Applied data analysis and modeling for energy engineers and scientists. New York: Springer.

Arnfield, J. (1975). A note on the diurnal, latitudinal and seasonal variation of the surface reflection coefficient. Journal of Applied Meteorology and Climatology, 1603-1605.

Backer, D., Ruschy, D., \& Wall, D. (1990). The albedo decay of prairie snows. Journal of Applied Meteorology(29), 179-187.

Carroll, J. J. (1985). Global transmissivity and diffuse fraction of solar radiation for clear and clody skies as measured and as predicted by bulk transmissivity models. Solar Energy, 35(2), 105-118.

Chen, A., Li, W., Li, W., \& Liu, X. (2014). An observational study of snow aging and the seasonal variation of snow albedo by using data from Col de Porte, France. Chinese Science Bulletin, 59(34), 48814889.

Cuevas, A., Luque, A., Eguren, J., \& DelAlamo, J. 5. (1982). $50 \%$ More output power from an albedocollecting flat panel using bifacial solar cells. Solar Energy, 419-420.

Dirmhirn, I., \& Eaton, F. (1975). Some characteristics of the albedo of snow. Journal of Applied Meteorology(14), 375-379.

Duffie, J., \& Beckman, W. (2013). Solar Engineering of Thermal Processes. Hoboken, New Jersey: John Wiley \& Sons, Inc.

Gardner, A., \& Sharp, M. (2010). A review of snow and ice albedo and the development of a new physically based broadband albedo parametrization. Journal of Geophysical Research, 115.

Gray, D. M., \& Landine, P. G. (1987). Albedo model for shallow prairie snow covers. Canadian Journal of Earth Science, 24, 1760-1768.

Gueymard, C. (1987). An isotropic solar irradiance model for tilted surfaces and its comparison with selected enegineering algorithms. Solar Energy, 38(5), 367386.

Hamilton, R. A., \& Collingbourne, R. H. (1967). A difficulty in the interpretation of certain radiation measurements. Quarterly Journal of the Royal Meteorological Society(93), 186-194.

Hunt, B. D., \& Calafell, D. O. (1977). Determination of average ground reflectivity for solar collectors. Solar Energy, 19, 87-89.

Kip and Zonen. (2013, November). Instruction manual: CMP series Pyranometer, CMA series Albedometer.

Kondo, J., \& Yamazaki, T. (1990). A predisction model for snowmelt, snow surface temperature and freezing depth using a heat balance method. Journal of Applied Meteorology, 29, 375-384.

Liu, B., \& Jordan, R. (1963). The long-term average performance of flat-plate solar energy collerctors. Solar Energy, 7, 53-74.

McKay, G. A. (1964). Relationship between snow survey and climatological measurements for the Canadian Great Plains. 32nd Annual Meeting of the Western Snow Conference.

Muneer, T. (1997). Solar Radiation and Daylight Models for the Energy Efficient Design of Buildings.

National Oceanic and Atmospheric Administration. (2017). SURFRAD Network. Retrieved 2018, from http://www.esrl.noaa.gov/gmd/grad/surfrad/

Nkendirim, L. (1972). A note on the albedo of surfaces. Journal of Applied Meteorology(11), 867-874.

Petzold, D. E. (1977). An estimation technique for snow surface albedo. Climatological Boulletin, McGill University, 21, 1-11.

Revesza, M., Oswaldb, S. M., Trimmelb, H., Weihsb, P., \& Zaminia, S. (2018). Potential increase of solar irradiation and its influence on PV facades inside an urban canyon by increasing the ground-albedo. Solar Energy, 7-15.

Slatyer, R. O., \& Mcllroy, I. C. (1961). Practical Microclimatology. Melbourne: CSIRO.

Sun, X., Khana, M. R., Delineb, C., \& Alama, M. A. (2018). Optimization and performance of bifacial solar modules: A global perspective. Applied Energy, 16011610.

Thevenard, D., \& Haddad, K. (2006). Ground reflectivity in the context of building energy simulation. Energy and Buildings(38), 972-980.

Winther, J.G. (1993). Short and long-term variability of snow albedo. Nordic Hydrology, 199-212. 
Table 1: Previous snow/ground reflectivity models for predicting reflectivity.

\begin{tabular}{|c|c|c|}
\hline Reflectivity Model & Input Data & Reference \\
\hline \multicolumn{3}{|l|}{ The Thevenard and Haddad simple model } \\
\hline $\begin{array}{l}\quad \rho_{g, i}=\rho_{\text {nosnow }} \cdot\left(1-\frac{N_{\text {snow }, i}}{N_{i}}\right)+\rho_{\text {snow }} \cdot \frac{N_{\text {snow }, i}}{N_{i}} \\
\text { where: } \\
\rho_{\text {nosnow }}-\text { snow-free reflectivity of ground } \\
\rho_{\text {snow }}-\text { snow reflectivity } \\
N_{\text {snow }, i}-\text { average number of days with snow in month i } \\
N_{i}-\text { number of days in month i }\end{array}$ & $\begin{array}{l}\text { - } \rho_{\text {nosnow }}-\text { snow-free reflectivity } \\
\text { of ground } \\
\text { - } \rho_{\text {snow }}-\text { snow reflectivity } \\
\text { - } N_{\text {snow }, i}-\text { average number of } \\
\text { days with snow in month } \mathrm{i} \\
\text { - } N_{i} \text { - number of days in month } \mathrm{i}\end{array}$ & $\begin{array}{l}\text { (Thevenard \& } \\
\text { Haddad, 2006) } \\
\text { follows } \\
\text { (Liu \& Jordan, } \\
\text { 1963) }\end{array}$ \\
\hline \multicolumn{3}{|l|}{ The Thevenard and Haddad advanced model } \\
\hline $\begin{array}{l}\text { - Assumes real historical record of snow depth is } \\
\text { available; } \\
\text { - If snow depth increases from the previous time step, } \\
\text { reflectivity is set to a high value; } \\
\text { - Reflectivity is then reduced with each passing day; } \\
\text { - Snow melt is determined applying a simple energy } \\
\text { balance at the surface of snow. } \\
\text { When snow is less than } 5 \mathrm{~cm} \text {, the following formula is } \\
\text { applied: } \\
\qquad \rho_{g}=\rho_{g, \text { nosnow }} \cdot\left(1-\frac{d}{d_{0}}\right)+\rho_{\text {snow }} \cdot \frac{d}{d_{0}} \\
\text { where: } \\
d-\text { snow depth } \\
d_{0}-\text { snow depth } 5 \text { cm } \\
\rho_{\text {snow }}-\text { reflectivity calculated for snow depth greater than } \\
5 \text { cm } \\
\rho_{g, \text { nosnow }}-\text { month dependent reflectivity }\end{array}$ & $\begin{array}{l}\text { - } d-\text { snow depth } \\
\text { - } d_{0}-\text { snow depth } 5 \mathrm{~cm} \\
\text { - } \rho_{g, \text { nosnow }- \text { month dependent }} \\
\text { reflectivity } \\
\text { - } \rho_{\text {snow }}-\text { snow reflectivity }\end{array}$ & $\begin{array}{l}\text { (Thevenard \& } \\
\text { Haddad, 2006) }\end{array}$ \\
\hline \multicolumn{3}{|l|}{ Other models for winter } \\
\hline $\begin{array}{l}\quad \rho=0.839-0.0473 \cdot n^{1 / 2} \\
\text { where: } \\
n-\text { number of days after snow-fall }\end{array}$ & - Number of days after snow-fall & $\begin{array}{l}\text { (Backer, Ruschy, } \\
\text { \& Wall, 1990) }\end{array}$ \\
\hline $\begin{array}{l}\quad \rho=\rho_{\min }+\left(\rho(0)-\rho_{\min }\right) \cdot e^{-\frac{n}{K}} \\
\text { where: } \\
\rho_{0}-\text { reflectivity of snow-fall day }(0.85) \\
\rho_{\min }-\text { converged reflectivity value } \\
n-\text { number of days after snow-fall } \\
K-\text { rate of decrease parameter }\end{array}$ & - Number of days after snow-fall & $\begin{array}{c}\text { (Kondo \& } \\
\text { Yamazaki, 1990) }\end{array}$ \\
\hline $\begin{array}{l}\qquad \rho=\rho_{t-1}-D R \cdot t \\
\text { where: } \\
\rho_{t-1}-\text { reflectivity from preceding day } \\
D R-\text { decay rate } \\
t-\text { days since the last snow-fall }\end{array}$ & $\begin{array}{l}\text { - Maximum temperature } \\
\text { - Net solar radiation } \\
\text { - Snow depth } \\
\text { - Starting reflectivity }\end{array}$ & $\begin{array}{c}\text { (Gray \& Landine, } \\
1987)\end{array}$ \\
\hline $\begin{array}{l}\text { For melting season: } \\
\qquad \rho=0.90-9.21 \times 10^{-4} \cdot T_{a c c}-0.0042 \cdot S R \\
\text { where: } \\
T_{a c c}-\text { accumulated daily maximum temperature index }\left({ }^{\circ} \mathrm{F}\right) \\
S R-\text { solar radiation }\left(\mathrm{mW} / \mathrm{cm}^{2}\right)\end{array}$ & $\begin{array}{l}\text { - Temperature } \\
\text { - Solar radiation }\end{array}$ & (Winther, 1993) \\
\hline \multicolumn{3}{|l|}{ Model for vegetated ground } \\
\hline $\begin{array}{l}\text { For vegetated ground: } \\
\qquad \rho=\rho_{0} \cdot e^{b z} \\
\text { where: } \\
\rho_{0} \text { - statistical estimate coefficient } \\
z-\text { solar zenith angle (degree) } \\
b \text { - coefficient describing the rate of reflectivity changing }\end{array}$ & $\begin{array}{l}\text { - Solar zenith angle } \\
\text { - Surface properties }\end{array}$ & (Arnfield, 1975) \\
\hline
\end{tabular}

